\title{
Assessment of Antioxidant Activity of Crude and Purified Bio-active Compound, Embelin in Aegiceras corniculatum (L.) Blanco: A Less-explored Mangrove Plant
}

\author{
Manisha Mohapatra, Uday Chand Basak* \\ Seed Bank and Seed Biology Division, Regional Plant Resource Centre, R\&D Institute of Forest and Environment, Department, \\ Government of Odisha Nayapalli, Bhubaneswar, Odisha, INDIA.
}

\begin{abstract}
Context: Most of the Mangrove species are vital basically in terms of economic, environmental and medicinal point of view as several Mangrove species are used for preparation of many drug formulations. In this aspect, Aegiceras corniculatum is a unique black Mangrove plant. Aim: In this study antioxidant potency of different parts of A. corniculatum was evaluated through measuring the antioxidant parameters along with a comparative assessment between the crude extracts and the purified embelin isolates. Settings and Design: For this purpose, two different extraction procedures were opted along with two different solvent systems to confirm the viability of antioxidant values obtained from different plant parts of Aegiceras corniculatum. Methods and Materials: Antioxidant parameters like Phenol, Flavonoid, Total antioxidant content, 2, 2-diphenyl1-picrylhydrazyl (DPPH), ferric reducing antioxidant power (FRAP), Reducing power were quantified from all the extracted plant part samples. Statistical analysis used: The results of the non-enzymatic parameters of antioxidant activity of both the crude plant extracts and the purified embelin samples were analysed through Two Way Repetitive Measure ANOVA using GRAPHPAD PRISM software version 6.05. Results: From the results, crude extracts along with isolated compounds had shown better antioxidant potency particularly in fruit followed by root, stem bark and leaf. Optimization of extraction process validated Soxhlet method to be a superior one. Conclusion: Crude extracts were found to be superior to purified isolates in terms of antioxidant potency. All samples showed remarkable antioxidant potency hence can be used in medicinal industries.
\end{abstract}

Key words: Aegiceras corniculatum, Antioxidant, DPPH, FRAP, Reducing Power.

Key messages: Validation of antioxidant potency through non enzymatic parameters analysis for various plant parts of Aegiceras corniculatum paved a path towards use of vegetative parts also for drug formulation. However comparative appraisal of crude and purified embelin isolates helped in assessing their potent quality.

\section{INTRODUCTION}

Substantial increase in the research pertaining to non-synthetic rather natural antioxidant bio molecules has been observed recently due to their natural origin, cost effectiveness, multifaceted activities and non or less toxicity. ${ }^{1,2}$ The interest in intake of natural antioxidant compounds related to herbal medicine is getting popularized leading towards concentrated and elaborate research in inventing new compounds of antioxidant worth. Antioxidant molecules are capable of inhibiting the oxidation of other molecules by neutralizing free radical intermediates. ${ }^{3,4}$ However, a number of synthetic antioxidants are having possible toxic and carcinogenic activities, while on the other hand for natural antioxidants, several health beneficial properties have been reported.
Submission Date: 16-02-2021; Revision Date: 12-04-2021; Accepted Date: 18-06-2021

DOI: 10.5530/ijper.55.3.152 Correspondence: Dr. Uday Chand Basak Seed Bank and Seed Biology Division, Regional Plant Resource Centre, R\&D Institute of Forest and Environment, Department, Government of Odisha Nayapalli, Bhubaneswar 751015,Odisha, INDIA. Phone no: +91 8895175345 E-mail: manishamohapatra7@gmail.com

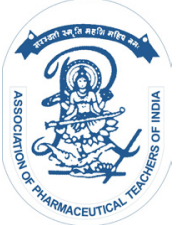

www.ijper.org 
The most fascinating bio-active compound in the benzoquinone group is embelin, mostly found in Myrsinaceae family. ${ }^{4}$ Besides several medicinal properties, it has evident antioxidant activity. ${ }^{5-11}$ However the alternative substitutive source of embelin has been found in Aegiceras corniculatum, a true mangrove plant ${ }^{12-16}$ with enriched antioxidant values. ${ }^{17,18}$

The main goal of current work is to establish antioxidant activity of each and every part of $A$. corniculatum and to know the efficacy of crude extracts and the purified embelin isolates in terms of their antioxidant potency.

The present piece of work has been taken forward to calculate antioxidant potency of the different plant parts of $A$. corniculatum thus validating the plant as a source of natural antioxidants.

\section{MATERIALS AND METHODS}

\section{Plant Material}

Aegiceras corniculatum (L.) Blanco matured plant parts (Leaves, Stem Bark, Roots and Fruits) were collected during the month of July, 2015 from Bhitarkanika mangrove forest areas of the Odisha coast, India $\left(20^{\circ} 18^{\prime}-20^{\circ} 32^{\prime} \mathrm{N}\right.$ and $\left.86^{\circ} 41^{\prime}-86^{\circ} 48^{\prime} \mathrm{E}\right)$. The sample species was compared with herbarium specimens present in the institutional herbarium (bearing voucher specimen no 4618) and also verified through the reference book "The Flora of Odisha". ${ }^{19}$

\section{Pre-treatment of Samples}

All the plant parts (Leaf, stem bark, fruit and root samples) were collected and shade dried and pulverizedinto fine powder. ${ }^{20}$

\section{Sample Extraction Extraction-1}

Powdered samples (leaf, stem bark, fruit and root) were extracted with methanol and chloroform separately for 16-18 hr using Soxhlet apparatus. ${ }^{15}$ Filtrates were collected, condensed and kept as stock solution.

\section{Extraction-2}

Powdered samples (leaf, stem bark, fruit and root) were extracted with methanol and chloroform separately at $60^{\circ} \mathrm{C}$ for a period of $12-14 \mathrm{hr}$ through water bath. ${ }^{21}$ Filtrates were collected, condensed and kept as stock solution.

\section{Total Phenol Content (TPC)}

Phenol content was estimated following the method of Swain and Hills with slight modification. ${ }^{22,23}$ Phenol content values were expressed as mg GAE/gm dry wt.

\section{Total Flavonoid Content (TFC)}

Total Flavonoid content (TFC) was measured by the Aluminium Chloride method. ${ }^{24}$ Quercetin was used as standard and the values were expressed as $\mathrm{mg} \mathrm{QE} / \mathrm{gm}$ dry wt.

\section{DPPH Free Radical Scavenging Activity}

DPPH free radical scavenging activity of the extracted and purified samples was measured following protocols of Brand-Williams. ${ }^{25}$ Ascorbic acid was used as standard. Radical Scavenging Activity of DPPH was calculated and expressed as \% scavenging activity. ${ }^{26}$

\section{$I_{50}$ value in DPPH Assay}

The $\mathrm{IC}_{50}$ values of each extracted and purified samples were determined graphically. The $\mathrm{IC}_{50}$ was defined as the concentration in $\mu \mathrm{g}$ of dry sample/ml that inhibits the formation of DPPH radicals by $50 \% .{ }^{27}$

\section{Phosphomolybdenum Reduction Assay}

The total antioxidant content of the extracted and purified samples was evaluated using the phosphomolybdenum method. ${ }^{28}$ The antioxidant content values were expressed as mg AAE/gm dry wt.

\section{Ferric Reducing Antioxidant Power (FRAP) Assay}

FRAP assay is used for measuring the total antioxidant capacity. ${ }^{29}$ The FRAP values were expressed in $\mathrm{mMol}$ ascorbic acid equivalent (AAE)/gm dry wt.

\section{Reducing Power Activity}

The reducing power of the sample was determined using potassium ferricyanide and ferric chloride. ${ }^{30,31}$ Ascorbic acid was used as standard and the reducing power values were expressed as $\mathrm{IC}_{50}$.

\section{Statistical Interpretation}

In present study, the results of the non-enzymatic parameters of antioxidant activity of both the crude plant extracts and the purified embelin samples were analysed through Two Way Repetitive Measure ANOVA using GRAPHPAD PRISM software version 6.05. All the data are expressed as Mean $\pm \mathrm{SD}$. All the percentile values were first converted into angular transformation value before statistical analysis. The variations in results were analysed at $99.9 \%$ significant level.

\section{RESULTS}

\section{Total Phenol Content (TPC)}

The total phenol content was assessed from different plant parts of both the crude extracts and purified isolates and was expressed in terms of $\mathrm{mg}$ GAE/gm 
dry wt. In case of $A$. corniculatum samples, TPC content in crude extracts was found to be in a range of 4.75$23.27 \mathrm{mg}$ GAE/gm dry wt. and in purified isolates $0.78-14.35 \mathrm{mg}$ GAE/gm dry wt. The fruit part showed highest total phenol content followed by root, stem bark and finally by leaf parts. The solvent systems used along with the methods involved for extraction had also played a crucial role in phenol content variations. When both crude extracts and purified isolates were compared, the crude extracts were found to be superior to the purified isolates. In a experiment similar type of difference in total phenol content of crude and partition extract of Dendrobium sabin flower was observed. ${ }^{32}$ In another study, crude extracts of Enbydra fluctuans Lour showed higher efficacy than the fractionated isolates. ${ }^{33}$ In the multiple comparison analysis, the row factor i.e. the plant parts extracts was found to be highly significant with $P$ value $<0.0001$, where as the column factor i.e. the crude and purified isolates were found to be significant at $P$ value 0.0003 (Table 1 ).

\section{Total Flavonoid Content (TFC)}

In case of $A$. corniculatum samples, TFC content in crude extracts was found to be in a range of $12.10-52.07 \mathrm{mg}$ $\mathrm{QE} / \mathrm{gm}$ dry wt. and in purified isolates $2.29-12.87 \mathrm{mg}$ QE/gm dry wt. Fruit part showed highest total Flavonoid content followed by root, stem bark and finally by leaf parts. The solvent systems used along with the methods involved for extraction had also played a crucial role in phenol content variations. When both crude extracts and purified isolates were compared, the crude extracts were found to be superior to the purified isolates. This data was validated by another experiment of antioxidant study in sweet potato leaf crude and fractionated extracts. ${ }^{34}$ In the multiple comparison analysis, both the row factor i.e. the plant parts extracted through different processes with various solvent systems and column factor i.e. the crude and purified isolates were found to be highly significant with $P$ value $<0.0001$ (Table 2).

\section{Total Antioxidant Content (TAC)}

TAC content in the crude extracts was found to be in a range of $0.54-2.1 \mathrm{mg} \mathrm{AAE} / \mathrm{gm}$ dry wt. $/ \mathrm{ml}$ and in purified isolates $0.13-0.41 \mathrm{mg} \mathrm{AAE} / \mathrm{gm}$ dry wt. $/ \mathrm{ml}$. The fruit part showed highest total antioxidant content in terms of non-enzymatic evaluation followed by root, stem bark and finally by leaf parts. Our result was being supported by findings of other work where similar pattern of total antioxidant content in different plant parts of Cucumis melo was seen. ${ }^{35}$ In the multiple comparison analysis, the row factor i.e. the plant parts extracted through different processes was found to be highly significant with $P$ value $<0.0001$, and the column factor i.e. the crude and purified isolates were found to be significant at $P$ value 0.0003 (Table 3).

\begin{tabular}{|c|c|c|c|c|}
\hline \multirow{2}{*}{ Plant Parts } & \multirow{2}{*}{ Extraction Process } & \multirow{2}{*}{ Solvents Used } & \multicolumn{2}{|c|}{ TPC Content (mg GAE/gm dry wt.) } \\
\hline & & & Crude & Pure \\
\hline \multirow{4}{*}{ FRUIT } & \multirow{2}{*}{ Soxhlet } & Methanol & $21.4 \pm 1.021(10)$ & $11.63 \pm 0.462(10)$ \\
\hline & & Chloroform & $23.27 \pm 2.003(10)$ & $14.35 \pm 2.631(10$ \\
\hline & \multirow{2}{*}{ Water bath } & Methanol & $18.36 \pm 2.661(10)$ & $4.53 \pm 0.092(10)$ \\
\hline & & Chloroform & $20.92 \pm 2.481(10)$ & $7.79 \pm 0.805(10)$ \\
\hline \multirow{4}{*}{ LEAF } & \multirow{2}{*}{ Soxhlet } & Methanol & $6.61 \pm 0.185(10)$ & $1.12 \pm 0.161(10)$ \\
\hline & & Chloroform & $7.76 \pm 0.081(10)$ & $1.33 \pm 0.244(10)$ \\
\hline & \multirow{2}{*}{ Water bath } & Methanol & $4.75 \pm 0.244(10)$ & $0.78 \pm 0.129(10)$ \\
\hline & & Chloroform & $5.97 \pm 0.881(10)$ & $0.88 \pm 0.081(10)$ \\
\hline \multirow{4}{*}{ STEM BARK } & \multirow{2}{*}{ Soxhlet } & Methanol & $8.32 \pm 2.541(10)$ & $1.44 \pm 0.161(10)$ \\
\hline & & Chloroform & $9.33 \pm 0.562(10)$ & $1.87 \pm 0.244(10)$ \\
\hline & \multirow{2}{*}{ Water bath } & Methanol & $8.19 \pm 2.313(10)$ & $1.28 \pm 0.161(10)$ \\
\hline & & Chloroform & $8.59 \pm 1.554(10)$ & $1.6 \pm 0.161(10)$ \\
\hline \multirow{4}{*}{ ROOT } & \multirow{2}{*}{ Soxhlet } & Methanol & $14.35 \pm 0.185(10)$ & $2.29 \pm 0.333(10)$ \\
\hline & & Chloroform & $15.15 \pm 0.514(10)$ & $2.99 \pm 0.369(10)$ \\
\hline & \multirow{2}{*}{ Water bath } & Methanol & $10.24 \pm 0.321(10)$ & $2.03 \pm 0.333(10)$ \\
\hline & & Chloroform & $11.15 \pm 0.647(10)$ & $2.88 \pm 0.847(10)$ \\
\hline
\end{tabular}

NB- Data are expressed as Mean \pm SD, (where $n=10)$ 


\begin{tabular}{|c|c|c|c|c|}
\hline \multirow{2}{*}{ Plant Parts } & \multirow{2}{*}{ Extraction Process } & \multirow{2}{*}{ Solvents Used } & \multicolumn{2}{|c|}{ TFC Content (mg QE/gm dry wt.) } \\
\hline & & & Crude & Pure \\
\hline \multirow{4}{*}{ FRUIT } & \multirow{2}{*}{ Soxhlet } & Methanol & $50.72 \pm 0.561(10)$ & $11.84 \pm 0.197(10)$ \\
\hline & & Chloroform & $52.07 \pm 0.649(10)$ & $12.87 \pm 0.374(10)$ \\
\hline & \multirow{2}{*}{ Water bath } & Methanol & $39.0 \pm 0.657(10)$ & $10.43 \pm 0.218(10)$ \\
\hline & & Chloroform & $48.94 \pm 0.191(10)$ & $11.12 \pm 0.225(10)$ \\
\hline \multirow{4}{*}{ LEAF } & \multirow{2}{*}{ Soxhlet } & Methanol & $18.89 \pm 0.261(10)$ & $4.16 \pm 0.056(10)$ \\
\hline & & Chloroform & $19.88 \pm 0.441(10)$ & $4.37 \pm 0.268(10)$ \\
\hline & \multirow{2}{*}{ Water bath } & Methanol & $12.10 \pm 0.471(10)$ & $2.29 \pm 0.036(10)$ \\
\hline & & Chloroform & $17.95 \pm 0.611(10)$ & $3.35 \pm 0.191(10)$ \\
\hline \multirow{4}{*}{ STEM BARK } & \multirow{2}{*}{ Soxhlet } & Methanol & $21.79 \pm 0.574(10)$ & $7.92 \pm 0.046(10)$ \\
\hline & & Chloroform & $23.76 \pm 0.191(10)$ & $8.11 \pm 0.051(10)$ \\
\hline & \multirow{2}{*}{ Water bath } & Methanol & $20.47 \pm 0.322(10)$ & $6.97 \pm 0.105(10)$ \\
\hline & & Chloroform & $20.91 \pm 0.381(10)$ & $7.74 \pm 0.141(10)$ \\
\hline \multirow{4}{*}{ ROOT } & \multirow{2}{*}{ Soxhlet } & Methanol & $38.29 \pm 0.835(10)$ & $9.51 \pm 0.174(10)$ \\
\hline & & Chloroform & $38.49 \pm 0.304(10)$ & $9.89 \pm 0.156(10)$ \\
\hline & \multirow{2}{*}{ Water bath } & Methanol & $24.91 \pm 0.768(10)$ & $8.3 \pm 0.147(10)$ \\
\hline & & Chloroform & $26.08 \pm 0.706(10)$ & $8.75 \pm 0.173(10)$ \\
\hline
\end{tabular}

NB- Data are expressed as Mean \pm SD, (where $n=10)$

\begin{tabular}{|c|c|c|c|c|}
\hline \multirow{2}{*}{ Plant Parts } & \multirow{2}{*}{$\begin{array}{l}\text { Extraction } \\
\text { Process }\end{array}$} & \multirow{2}{*}{ Solvents Used } & \multicolumn{2}{|c|}{ TAC Content (mg AAE/gm dry wt./ml) } \\
\hline & & & Crude & Pure \\
\hline \multirow{4}{*}{ FRUIT } & \multirow{2}{*}{ Soxhlet } & Methanol & $2.09 \pm 0.017(10)$ & $0.39 \pm 0.084(10)$ \\
\hline & & Chloroform & $2.1 \pm 0.042(10)$ & $0.41 \pm 0.013(10)$ \\
\hline & \multirow{2}{*}{ Water bath } & Methanol & $1.54 \pm 0.022(10)$ & $0.37 \pm 0.117(10)$ \\
\hline & & Chloroform & $1.73 \pm 0.232(10)$ & $0.38 \pm 0.021(10)$ \\
\hline \multirow{4}{*}{ LEAF } & \multirow{2}{*}{ Soxhlet } & Methanol & $0.55 \pm 0.042(10)$ & $0.13 \pm 0.011(10)$ \\
\hline & & Chloroform & $0.56 \pm 0.042(10)$ & $0.15 \pm 0.011(10)$ \\
\hline & \multirow{2}{*}{ Water bath } & Methanol & $0.54 \pm 0.125(10)$ & $0.13 \pm 0.046(10)$ \\
\hline & & Chloroform & $0.543 \pm 0.006(10)$ & $0.14 \pm 0.066(10)$ \\
\hline \multirow{4}{*}{ STEM BARK } & \multirow{2}{*}{ Soxhlet } & Methanol & $0.69 \pm 0.061(10)$ & $0.23 \pm 0.121(10)$ \\
\hline & & Chloroform & $0.73 \pm 0.011(10)$ & $0.25 \pm 0.011(10)$ \\
\hline & \multirow{2}{*}{ Water bath } & Methanol & $0.673 \pm 0.023(10)$ & $0.24 \pm 0.052(10)$ \\
\hline & & Chloroform & $0.69 \pm 0.057(10)$ & $0.23 \pm 0.023(10)$ \\
\hline \multirow{4}{*}{ ROOT } & \multirow{2}{*}{ Soxhlet } & Methanol & $1.01 \pm 0.117(10)$ & $0.33 \pm 0.117(10)$ \\
\hline & & Chloroform & $1.02 \pm 0.053(10)$ & $0.35 \pm 0.094(10)$ \\
\hline & \multirow{2}{*}{ Water bath } & Methanol & $0.93 \pm 0.011(10)$ & $0.31 \pm 0.011(10)$ \\
\hline & & Chloroform & $0.96 \pm 0.043(10)$ & $0.32 \pm 0.022(10)$ \\
\hline
\end{tabular}

NB- Data are expressed as Mean \pm SD, (where $n=10)$ 


\section{Percentage of Radical Scavenging Activity (RSA)}

The radical-scavenging activity in the crude extracts was found to be in a range of 39.13-65.18\% dry wt. and in the purified isolates in a range of 51.6-72.16\% dry wt. The fruit part showed highest radical-scavenging activity followed by root, stem bark and finally by leaf parts. This data was supported by similar kind of work where radical scavenging activities of leaf, stem bark, root, flower and fruit of Bligbia unijugata Baker was measured. ${ }^{36}$ In the multiple comparison analysis, the row factor i.e. the plant parts extracted through different processes with various solvent systems was found to be highly significant with $P$ value $<0.0001$, where as the column factor i.e. the crude and purified isolates were found to be significant at $P$ value 0.0003 (Figure 1).

\section{DPPH Radical Scavenging Activity $\left(\mathrm{IC}_{50}\right)$}

The DPPH radical-scavenging activity in the crude extracts was found to be in a range of $12-40 \mu \mathrm{g}$ of dry wt. $/ \mathrm{ml}$. and in the purified isolates in a range of 33-100 $\mu \mathrm{g}$ of dry wt. /ml. The fruit part showed highest radical-scavenging activity followed by root, stem bark and finally by leaf parts. Our result was being supported by findings of other work where similar pattern of DPPH radical scavenging activity in different plant parts of Cucumis melo was seen. ${ }^{35}$ The following sequence of scavenging activity in the plant parts was also partly supported by antioxidant activity study of methanolic extracts from different parts of Morus alba. ${ }^{37}$ In the multiple comparison analysis, the row factor i.e. the plant parts extracted through different processes with various solvent systems was found to be highly significant with $P$ value $<0.0001$, whereas the column factor i.e. the crude and purified isolates were found to be significant at $P$ value 0.0003 (Figure 2).

\section{Ferric Reducing Antioxidant Power (FRAP)}

The FRAP activity in the crude extracts was found to be in a range of 1.4-7.1 mg AAE/gm dry wt. and in purified isolates in a range of $0.1-0.46 \mathrm{mg}$ AAE/gm dry wt. The

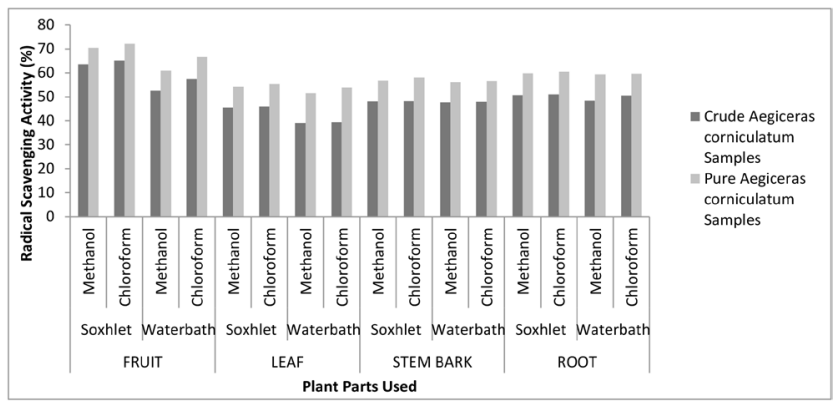

Figure 1: Percentage of Radical Scavenging Activity of Crude extracts and Purified Embelin Compounds of $A$. corniculatum.

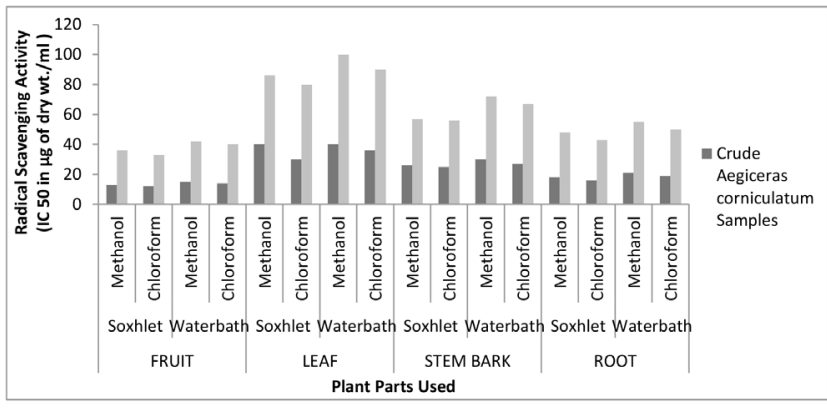

Figure 2: DPPH Radical Scavenging Activity (IC $\mathrm{C}_{50}$ Value) of Crude extracts and Purified Embelin Compounds of A. corniculatum.

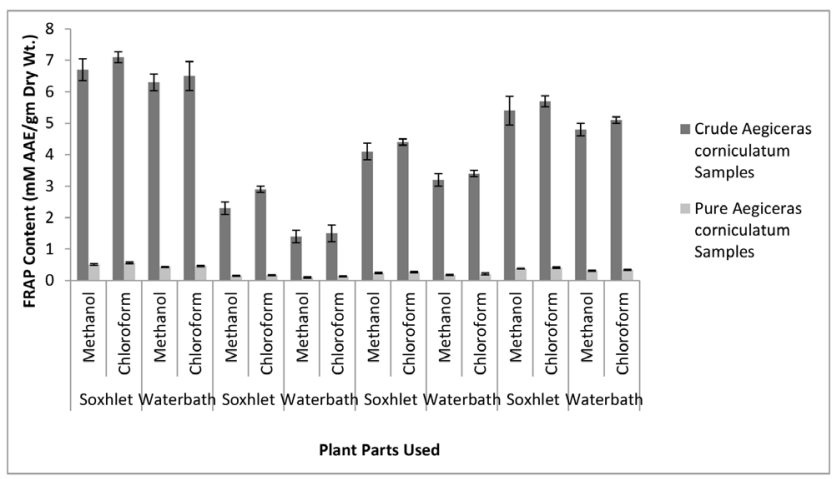

Figure 3: Ferric Reducing Antioxidant Power Activity (mM AAE/g dry wt.) of Crude extracts and Purified Embelin Compounds of $A$. corniculatum.

fruit part showed highest radical-scavenging activity followed by root, stem bark and finally by leaf parts. Our result was being supported by findings of other work where similar pattern of DPPH radical scavenging activity in different plant parts of Cucumis melo was seen..$^{35}$ All data were analysed statistically at $99.9 \%$ interval level through two ways RM ANOVA along with Sidak's multiple comparisons test. In the multiple comparison analysis, the row factor i.e. the plant parts extracted through different processes with various solvent systems was found to be highly significant with $P$ value $<0.0001$, whereas the column factor i.e. the crude and purified isolates were found to be significant at $P$ value 0.0002 (Figure 3).

\section{Reducing Power Activity}

In case of $A$. corniculatum samples, reducing power activity in the crude extracts was found to be in a range of 40-66 $\mu \mathrm{g}$ of dry wt. $/ \mathrm{ml}$. and in purified isolates in a range of $61-85 \mu \mathrm{g}$ of dry wt. / $\mathrm{ml}$. The fruit part showed effective reducing power activity followed by root, stem bark and finally by leaf parts. This work was validated by another study in which antioxidant activity of different plant parts of Sida cordifolia were assessed. ${ }^{38}$ In the multiple 


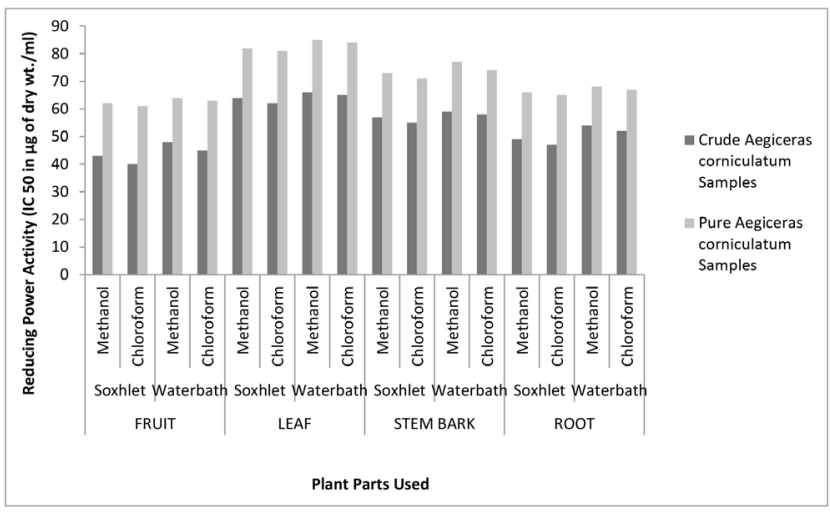

Figure 4: Reducing Power Activity ( $\mathrm{IC}_{50}$ in $\mu \mathrm{g}$ of dry wt./ml) of Crude extracts and Purified Embelin Compounds of A. corniculatum.

comparison analysis, the row factor i.e. the plant parts extracted through different processes with various solvent systems was found to be highly significant with $P$ value $<0.0001$, whereas the column factor i.e. the crude and purified isolates were found to be significant at $P$ value 0.0003 (Figure 4).

\section{DISCUSSION}

Embelin is one of the biologically active benzoquinone derivatives that can be used in several medicament purposes. This is one of the vital secondary metabolites, capable of inhibiting the harmful effects of free radicals. ${ }^{39}$ Due to high sensitivity and versatile medicinal applications of embelin compound; alternative source of its occurrence has been in a verge of search. A. corniculatum is a least concerned special group of Mangrove plant having embelin as the bio-active compound.

The antioxidant activity of all the plant parts was being validated by several other references. The antioxidant activity of $A$. corniculatum has been quantified by several other authors. The antioxidant activity in fruit parts of A. corniculatum have been evaluated by measuring TPC content and DPPH free radical scavenging activity. ${ }^{40}$ In most of the cases only the fruit parts were used as target sample to evaluate the antioxidant activity. However no concrete evidences regarding the antioxidant study in other plant parts besides the fruits are available. In our study we have focused our concern on the evaluation of the antioxidant activity in all the plant parts of the selected plant to find out the most potent source for natural antioxidant activity.

However utilization of crude plant extracts as antioxidants instead of using the eluted pure compounds is a favourable alternative from an economic and time saving point of view. In some cases these crude extracts have also been proved to be superior to that of the synthetic compounds as the other bio constituents present in the crude extracts may act synergistically to produce higher antioxidant potency. ${ }^{41}$ Furthermore comparative analysis of crude extracts with purified embelin compounds for antioxidant activity was an interesting area to find out the more potent source as antioxidant compound. This fact of superiority of crude extracts over purified compounds in terms of antioxidant activity was supported by several other researchers. ${ }^{42-44}$ Basically the more phenolic compounds present in the plant sample attributes to more antioxidant activity. ${ }^{35,37}$ The antioxidant potency of fruit parts in several other plants were also found to be superior than compared to leaf parts, which supported our study. ${ }^{35,37,45}$ In several studies this pattern may change that depends mostly upon presence of phenolic content in the plant parts.

\section{CONCLUSION}

The present piece of work gives a detailed view on the antioxidant activity of all the plant parts of $A$. corniculatum keeping in view on its non-enzymatic antioxidant activity. The crude extracts and embelin isolates had shown better antioxidant potency particularly in the fruit parts and lowest in leaf parts. When both the crude extracts and purified isolates were compared for antioxidant potency, the crude extracts were found to be superior to that of the purified isolates. Hence both the crude formulation and the purified compound can be used in drug formulation industries after further elaborate studies.

\section{ACKNOWLEDGEMENT}

The authors are highly thankful to National Medicinal Plants Board (NMPB), Govt. of India for providing financial support through Project Grant vide project no. R\&D/OR-01/2017

\section{CONFLICT OF INTEREST}

The authors declare no conflict of interest.

\section{ABBREVIATIONS}

DPPH: 2-diphenyl-1-picrylhydrazyl; FRAP: Ferric Reducing Antioxidant Power; AAE: Ascorbic Acid Equivalent; GAE: Gallic Acid Equivalent; QE: Quercetin Equivalent; TPC: Total Phenol Content; TFC: Total Flavonoid Content; TAC: Total Antioxidant Content. 


\section{REFERENCES}

1. Saito M, Sakagami H, Fujisawa S. Cytotoxicity and apoptosis induction by butylated hydroxyanisole (BHA) and butylated hydroxytoluene (BHT). Anticancer Res. 2003;23(6C):4693-701. PMID 14981915.

2. Kamat JP, Mishra KP. Herbal drugs in radioprotection: modulation by phytochemicals. In: Sharma RK, editor. Arora R. editors. Herbal Drug Research $21^{\text {st }}$ Century Prospective, Jaypee, New Delhi. 2006. p. 557-67.

3. Pisoschi AM, Negulescu GP. Methods for Total Antioxidant Activity Determination: A Review. Biochem and Anal Biochem. 2012;01(1). doi: 10.4172/2161-1009.1000106.

4. Radhakrishnan N, Gnanamani A. 4-benzoquinone (embelin)-A second solid gold of India-A Review. Int J Pharm. 2014;6:23-30;2:5-dihydroxy-3-undecyl-1.

5. Mishra $\mathrm{S}$, Das $\mathrm{AB}$. Effect of $\mathrm{NaCl}$ on leaf salt secretion and antioxidative enzyme level in roots of a mangrove, Aegiceras corniculatum. Indian J Exp Biol. 2003;41(2):160-6. PMID 15255609.

6. Joshi R, Ghanty TK, Mukherjee T. Formation of semiquinone radical in the reaction of embelin (2, 5-dihydroxy-3-undecyl-1,4-benzoquinone) with reductants as well as oxidants. Characterization by pulse radiolysis and structure investigation by quantum chemical study. J Mol Struct. 2009;928(13):46-53. doi: 10.1016/j.molstruc.2009.03.010.

7. Dai Y, Desano J, Qu Y, Tang W, Meng Y, Lawrence TS, et al. Natural IAP inhibitor embelin enhances therapeutic efficacy of ionizing radiation in prostate cancer. Am J Cancer Res. 2011;1(2):128-43. PMID 21804946.

8. Wei SD, Lin YM, Liao MM, Zhou HC, Li YY. Characterization and antioxidative properties of condensed tannins from the mangrove plant Aegiceras corniculatum. J Appl Polym Sci. 2012;124(3):2463-72. doi: 10.1002/ app.35258.

9. Roome T, Dar A, Ali S, Naqvi S, Choudhary MI. A study on antioxidant, free radical scavenging, anti-inflammatory and hepatoprotective actions of Aegiceras corniculatum (stem) extracts. J Ethnopharmacol. 2008;118(3):514-21. doi: 10.1016/j.jep.2008.05.021, PMID 18602778.

10. Powar PS, Gaikwad DK. Quantification of phytochemicals from some mangrove bark. Indian J Adv Plant Res. 2014;1:5-9.

11. Das A. Characterization Of Antioxidants And Antioxidative Properties Of Various Unifloral Honeys Procured From West Bengal, India. IOSR-JESTFT. 2013;7(3):56-63. doi: 10.9790/2402-0735663.

12. Alongi DM. Paradigm shifts in Mangrove Biology. In: Perillo GME, Wolanski E, Cahoon DR, Brinson MM, editors. $22^{\text {nd }}$ vol. Coastal Wetlands, an integrated ecosystem approach. Elsevier Science; 2009. p. 615-40.

13. Balasubramanian T, Khan SA. In Seshaiyana, ENVIS Newsletter on Indian Estuaries, Mangroves. $12^{\text {th }}$ vol. Coral Reefs and lagoons. Environmental Information System. Ministry of the Environment and Forests Government of India; 2014. p. 7.

14. Bandaranayake WM. Bioactivities, bioactive compounds and chemical constituents of mangrove plants. Wetlands Ecol Manag. 2002;10(6):421-52. doi: 10.1023/A:1021397624349.

15. Thota SPR, Sarma NS, Murthy YLN. A new embelin from the mangrove Aegiceras corniculatum. Indian J Chem. 2016;55B:123-7.

16. Rahman MM, Khan MA. Anti-cancer potential of South Asian plants. Nat Prod Bioprospect. 2013;3(3):74-88. doi: 10.1007/s13659-013-0027-6.

17. Bandaranayake WM. Traditional and medicinal uses of mangroves. Mangroves Salt Marshes. 1998;2(3):133-48. doi: 10.1023/A:1009988607044.

18. Ramchoun M, Harnafi H, Alem C, Benlys M, Elrhaffari L, Amrani S. Study on antioxidant and hypolipidemic effects of polyphenol rich extract from Thymus vulgaris and Lavandula multifida. Pharmacogn Res. 2009;1:106-12.

19. Saxena HO, Brahmam M. The flora of Orissa. $3^{\text {rd }}$ vol. Regional Research Laboratory and Orissa Forest Development Corporation Ltd. 1995. p. 1554-6.

20. Khamsah SM, Akowah G, Zhari I. Antioxidant activity and phenolic content of Orthosiphon st amineusBenth from different geographical origin. J Sustainability Sci Manag. 2006;1:14-20.

21. Ganesan B, Perumal P, Manickam VB, Gotteti SD, Srikakolapu SR, Thirumurthy LS. Optimization of extraction conditions for embelin in Embelia ribes by UV spectrophotometry. Achieves Appl Sci Res. 2010;2:49-53.
22. Swain T, Hillis WE. The phenolic constituents of Prunus domestica. I.- the quantitative analysis of phenolic constituents. J Sci Food Agric. 1959;10(1):63-8. doi: 10.1002/jsfa.2740100110.

23. Basak UC, Das AB, Das P. Chlorophyll, Carotenoids, protein S and Secondary Metabolites in leaves of 14 species of mangrove. Bull Mar Sci. 1969;58:654-9.

24. Zhishen J, Mengcheng $\mathrm{T}$, Jianming $\mathrm{W}$. The determination of flavonoid contents in mulberry and their scavenging effects on superoxide radicals. Food Chem. 1999;64(4):555-9. doi: 10.1016/S0308-8146(98)00102-2.

25. Brand-Williams W, Cuvelier ME, Berset C. Use of a free radical method to evaluate antioxidant activity. LWT - Food Science and Technology. 1995;28(1):25-30. doi: 10.1016/S0023-6438(95)80008-5.

26. Shyma TB, Deviprasad AG, Raghavendra MP. Assessment of antioxidant activity, total phenolic content of some medicinal plants used by the tribes in Wayanad, Kerala. J Chem Pharm Res. 2012;4:4501-5.

27. Ferreira ICFR, Baptista P, Vilas-Boas M, Barros L. Free-radical scavenging capacity and reducing power of wild edible mushrooms from northeast Portugal: individual cap and stipe activity. Food Chem. 2007;100(4):1511-6. doi: 10.1016/j.foodchem.2005.11.043.

28. Mani R, Ashraful Md, Raushanara A, Rumana J. In vitro free radical Scavenging Activity of Ixora coccinea L. Bangladesh J Pharmacol. 2008;3:90-6.

29. Benzie IFF, Strain JJ. The ferric reducing ability of plasma (FRAP) as a measure of "antioxidant power": the FRAP assay. Anal Biochem. 1996;239(1):70-6. doi: 10.1006/abio.1996.0292, PMID 8660627.

30. Oyaizu M. Studies on products of browning reaction. Antioxidative activities of products of browning reaction prepared from glucosamine. Jpn J Nutr Diet. 1986;44(6):307-15. doi: 10.5264/eiyogakuzashi.44.307.

31. Hazra B, Biswas S, Mandal N. Antioxidant and free radical scavenging activity of Spondias pinnata. BMC Complement Altern Med. 2008;8:63. doi: 10.1186/1472-6882-8-63, PMID 19068130.

32. Abu F, Mat Taib CN, Mohd Moklas MA, Mohd Akhir S. Antioxidant Properties of Crude Extract, Partition Extract, and Fermented Medium of Dendrobium sabin Flower Evid Based Complement Alternat Med. 2017;2017:2907219. doi: 10.1155/2017/2907219. PMID 28761496.

33. Sannigrahi S, Kanti Mazuder U, Kumar Pal D, Parida S, Jain S. Antioxidant potential of crude extract and different fractions of Enhydra fluctuans Lour. Iran J Pharm Res. 2010;9(1):75-82. PMID 24363710.

34. Zhang C, Liu D, Wu L, Zhang J, Li X, Wu W. Chemical Characterization and Antioxidant Properties of Ethanolic Extract and Its Fractions from Sweet Potato (Ipomoea batatas L.) Leaves. Foods. 2019;9(1):15-28. doi: 10.3390/ foods9010015, PMID 31877941.

35. Gopalasathees KK, Kalaichelvan VK. Antioxidant potential of different parts (leaves, stem, fruit, seed, flower and root) extracts of Cucumis melo VAR AGRESTIS. Int J Pharm Sci Res. 2021;12(1):465-9.

36. Ajiboye CO, Moronkola DO, Adesomoju AA. DPPH free radical scavenging activities of leaf, stem bark, root, flower and fruit of Blighia unijugata Baker (Sapindaceae) extracts, J Chem Biol. Physiol Sci. 2017;7(4):1190-7.

37. Khan MA, Rahman AA, Islam S, Khandokhar P, Parvin S, Islam MB, et al. A comparative study on the antioxidant activity of methanolic extracts from different parts of Morus alba L. (Moraceae). BMC Res Notes. 2013;6:24. doi: 10.1186/1756-0500-6-24, PMID 23331970.

38. Dhalwal K, Deshpande YS, Purohit AP, Kadam SS. Evaluation of the antioxidant activity of Sida cordifolia. Pharm Biol. 2005;43(9):754-61. doi: 10.1080/13880200500406438.

39. Shahidi F, Amarowicz R, Abou-Gharbia HA, Shehata AAY. Endogenous antioxidants and stability of sesame oil as affected by processing and storage. J Am Oil Chem Soc. 1997;74(2):143-8. doi: 10.1007/s11746-997-0159-0.

40. Banerjee D, Chakrabarti S, Hazra AK, Banerjee S, Ray J, Mukherjee B. Antioxidant activity and total phenolics of some mangroves in Sunderbans. Afr Biotechnol. 2008;7:805-10.

41. González J, Cruz JM, Domínguez H, Parajó JC. Production of antioxidants from Eucalyptus globulus wood by solvent extraction of hemicellulose hydrolysates. Food Chem. 2004;84(2):243-51. doi: 10.1016/S03088146(03)00208-5. 

extract and pure compounds of Acer ginnala Max. Bull Korean Chem Soc. 2004;25(3):389-91. doi: 10.5012/bkcs.2004.25.3.389 antioxidant activity of Pongamia pinnata Linn. Leaves extracts and isolated compound. Int J Pharm Biol Arch. 2010;1:69-75.
44. Rout SK, Kar DM, Maharana L. Evaluation of antimicrobial, antioxidant and wound healing Activity of different fractions of methanolic Extract of nerium oleander Linn. Int J Drug Dev Res. 2014;6:241-51.

45. Feduraev P, ChupakhinA G, Maslennikov P, Tacenko N, Skrypnik L. Variation in phenolic compounds Content and Antioxidant Activity of Different Plant Organs from Rumex crispus L. and Rumex obtusifolius L. at Different Growth Stages. Antioxidants (Basel). 2019;8(7):237-51. doi: 10.3390/antiox8070237, PMID 31340505.

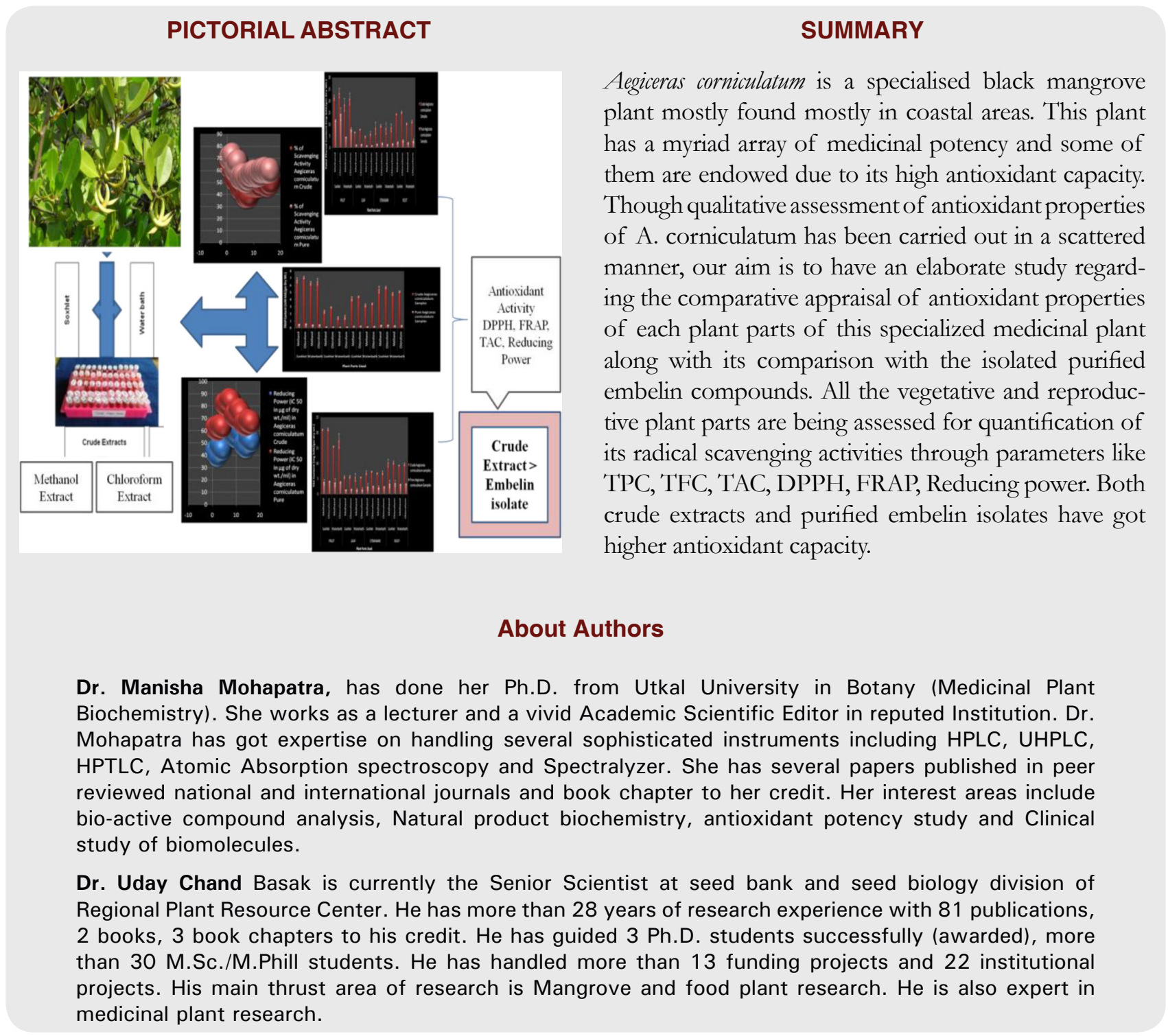

Cite this article: Mohapatra M, Basak UC. Assessment of Antioxidant Activity of Crude and Purified Bio-active Compound, Embelin in Aegiceras corniculatum (L.) Blanco: A Less-explored Mangrove Plant. Indian J of Pharmaceutical Education and Research. 2021;55(3):793-800. 